\title{
Руциинская И.И.
}

\section{Чаепитие в английской живописи викторианской эпохи}

Аннотация: Предметом исследования являются «чайные сюжеты» в английской бытовой живописи середины-второй половины ХІХ столетия. Их популярность и чрезвычайно широкое распространение, неизменно возраставшие на протяжении всего указанного периода, позволяют рассматривать живопись как важный инструмент «цивилизационного присвоения» чая британской культурой. Формируя узнаваемый визуальный образ английского чаепития во всем своеобразии его социальных, бытовых и гендерных проявлений, художественные произведения участвовали в процессе превращения импортируемого товара в национальный символ страны. Предложенный в статье анализ живописных работ предполагает не только изучение особенностей изображенного предметного мира, исторически и культурно детерминированных деталей чайного антуража и чайного этикета, но и выявление стоящих за ними национальных стереотипов, норм, системы ценностей. Обращение к изобразительным источникам позволяет существенно расширить источникую базу исследования и выйти на изучение визуальных кодов, визуальных стереотипов, визуальных представлений о нормах повседневной действительности. Несмотря на то, что в последние годы национальные гастрономические практики все чаще привлекают внимание ученых, в отечественной историографии данная тема исследуется впервые.

Ключевъе слова: Чай, английской чаепитие, викторианская эпоха, визуальные коды, живопись, повседневные практики, жанр, национальный символ, буржуазный, дом .

Review: For many years Britain has been associated with tea. In spite of being a national symbol of the UK, tea has always been an imported drink, therefore it has been strongly connected to the culture of the country of its origin. The process of tea assimilation in Britain took a long time. It was during the Victorian Era of British history when Eastern (Chinese) allusions were removed from a process of tea consumption. National painting played a significant role in the evolution of tea image. It shaped «visual codes» of British tea and proliferated the image of tea as a symbol of contemporary life. The subject of the research is the 'tea plots' in English genre painting of the middle and the second half of the XIXth century. Their increasing popularity and commonness in the aforesaid period allow to view art as an important instrument of the 'civilizational adoption' of tea by the British culture. Through creating a recognizable visual image of the English tea party with all its social, genre and gender peculiarities, pieces of artwork participated in the process of turning the imported product into the national symbol of the country. The analysis of paintings offered by the author of the article involves not only studying peculiarities of the world of objects depicted therein, historically and culturally determined details of the tea party and etiquette but also defining national stereotypes, norms and values behind them. The author appeals to pictorial sources which allows to extend the basis of the research and study the visual codes, visual stereotypes and visual attitudes to everyday life. Despite the fact that national gastronomical practices have recently attracted many scientists, this topic is studied for the first time in Russian historiography.

Keywords: House, bourgeois, national symbol, genre, everyday practices, fine arts, visual codes, Victorian Era, English tea party, tea.

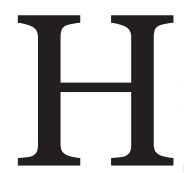
a протяжении второй половины XVII и всего XVIII века чай для жителей Великобритании оставался дорогостоящим экзотическим напитком, сохранявшим свою «нездешнюю» восточную природу, свою связь с иной, неевропейской культурой. Вместе с чайными листьями в страну ввозили дорогой китайский фарфор, аксессуары, мебель. Чайный стол в итоге был полем чрезвычайно интенсивного китайско-английского диалога.

Избавиться от «восточного акцента» чайной церемонии англичанам удалось лишь в викторианскую эпоху. Именно за годы уникально-продолжительного - шестидесятичетырехлетнего - периода царствования королевы Виктории (1837-1903 гг.) чай обрел статус национального напитка. 
Это связано, прежде всего, с изменением масштабов его потребления, за которым стояли имперские амбиции государства и коммерческие интересы набирающей силы буржуазии. Возрастающие объемы поставок, обеспечивались целым рядом целенаправленных действий. К ним относятся и постоянные дипломатические переговоры, и так называемые «опиумные войны», и беспрецедентное уменьшение налога на чай, и введение закона об ограничении продажи спиртных напитков и поддержке продажи чая, кофе, шоколада, и создание индийских и цейлонских чайных плантаций, и многое другое. В итоге чай стал доступным товаром, который во второй половине XIX века пили все: от членов царской семьи до рабочих.

Однако, для определения значимости напитка в структуре гастрономической идентичности народа важны не только количественные показатели его потребления. Механизмы ассимиляции чая включали создание особого - «истинно английского» - материального и визуального контекста чаепития, вытеснявшего из данной церемонии любые «восточные аллюзии». Уже во второй половине XVIII века появился фарфор собственного изготовления, а также чайная мебель, серебряная посуда. Их производство в последующие десятилетия обрело поистине массовые масштабы. В викторианскую эпоху возникла мода на особые скатерти, салфетки, даже на специальные платья и костюмы для «five o'clock». Чайное застолье стало органической частью английской культуры повседневности.

Изменение внешнего антуража сопровождалось формированием специфического английского чайного этикета. В XIX веке появились книги, регламентирующие все аспекты и детали чайной церемонии: как приготовить чай, как и где его подать, кого пригласить к чаю, о чем беседовать за столом. Показательно, что в викторианской этикетной традиции наряду с нормами того, как необходимо себя вести, чрезвычайно подробно прописывались запретительные правила: нельзя отхлебывать чай из чашки, в которой оставлена чайная ложка; нельзя смотреть на окружающих, когда делаешь глоток; нельзя отставлять мизинец, держа чашку; нельзя дамам вытирать губы салфеткой; нельзя класть салфетку на стол, выходя из-за чайного стола (только на стул) и т.д. и т.д. Нюансировка подобных запретов была чрезвычайно высокой и ярко отражала представления британского общества о приличиях и - что особенно волновало англичан - о неприличиях в поведении.

Переход от ритуала к этикету, к созданию целого свода национально детерминированных правил поведения за чайным столом знаменовал новый этап цивилизационного присвоения напитка, завершение его «перекодировки».

Кроме перечисленных, существовал еще один механизм «встраивания» чая в английскую культуру: создание устойчивой визуальной формулы английского чаепития. Значительную роль в этом процессе, как показало интересное исследование английского автора Э. Беддоес, играла реклама [1]. Не менее «влиятельной» оказалась и национальная живопись. К сожалению, в указанной работе, автор, философ по образованию, данную тему затрагивает бегло, а она, на наш взгляд, заслуживает более внимательного изучения.

Пожалуй, нигде и никогда больше чаепитие не привлекало к себе такого пристального внимания художников, как в Великобритании викторианской эпохи. К этой теме обращались мастера известные и не очень, столичные и провинциальные.

Первое, что бросается в глаза, когда рассматриваешь многочисленные полотна с изображением чайной церемонии, выполненные во второй половине XIX - начале XX в., как уютен мир, в котором все это происходит. Уютен, меблирован, буржуазен. Казалось бы, в подобных интонациях не должно быть ничего неожиданного, ведь чай и есть тот напиток, который сопровождает человека в минуты домашнего умиротворения, олицетворяет обывательские радости жизни. Однако в русской живописи того же времени чаепитие было не только повествованием о тихом домашнем бытии. Очень часто оно становилось формой рассказа о том, как разрушаются миры, сходят с исторической арены целые сословия, или о том, как безжалостен и равнодушен может быть человек по отношению к своему ближнему. Решая обличающие задачи, русские художники нередко заставляли своих персонажей пить чай в интерьерах оставленных хозяевами домов, на фоне полуразрушенных усадеб, на дороге, в многолюдных фойе неуютных гостиниц.

Подобного чайного антуража мир викторианской живописи не знал. Для чаепития здесь существовало только две разновидности окружения: либо хорошо обставленные интерьеры, либо красивые пейзажи. 
В этом мире не было места для чего-то плохого, несправедливого, некрасивого или (не дай бог!) «неприличного», выходящего за пределы общепринятой нормы. Чайный сюжет в трактовке викторианских художников никогда не становился поводом для социальной критики. Допускалась только легкая ирония по поводу нравов и привычек обывателей. Полотна буквально источали покой и довольство, если не сказать, вслед за историком искусства Н. Певзнером, самодовольство.

Живописные сцены чаепития были наглядным воплощением Великобритании как «рая благополучной буржуазии». Так, на картине Джорджа Гудвина Килберна «Чаепитие» (George Goodwin Kilburne «Tea Time») две девушки встречают вернувшегося домой отца. Одна подает ему чашку чая, другая домашние туфли. Они - приветливы и заботливы, он - благосклонен, патриархален, убелен сединами. Как и во многих других работах Килберна, действие отнесено в недалекое прошлое: костюмы, детали обстановки указывают на первую половину XIX столетия. Однако характер взаимодействия между персонажами, а также разработанная трактовка сюжета, где каждому действующему лицу отведена своя роль, прописано собственное амплуа, безошибочно указывают на викторианскую эпоху. Здесь все образцово, все правильно, все может служить примером для зрителя. Мужчина сидит - девушки суетятся, человек преклонных лет смотрит на молодые создания по-отечески снисходительно, а они на него - почтительно. Никто не выходит за пределы своей роли, которая, как в викторианском романе, считывается сразу. Каждый персонаж при всей своей индивидуальности является олицетворением определенного человеческого типа. И каждый из них вписывается в викторианские представления о порядке и норме.

Подобный порядок царит на десятках и сотнях английских полотен второй половины XIX - начала XX вв. Сидит у камина пожилая дама с чашкой чая на картине Г. Спенсеpa Тозера «Время чая» (Henry Spernon Tozer «Time for Теа»). Окружающий ее интерьер наполнен трогательными деталями, он прост и лучится почти сказочными интонациями: так описывают в детской литературе милых добрых бабушек. И так же, как в сказке, покоен, светел и добр изображенный мир, не содержащий ни одной тревожной ноты.

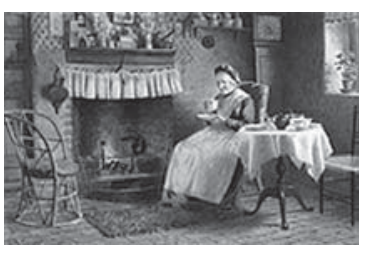

1. Г. С. Тозер. Время чая

Собрались за чайным столом подруги на картине Альберта Линча «Женщины, принимающие чай» (Albert Lynch «Women taking tea»). Они красивы, молоды, приветливы. В отличие от закрытых, интерьерных полотен Килберна и Тозера, пространство на картине А. Линча открыто окружающему пейзажу: распахнуты двери веранды, где происходит чаепитие, вливается через большие окна яркий летний свет. Природа на викторианских полотнах не вносит диссонанса в мир человека, напротив, призвана подчеркнуть его благоустроенность и гармоничность.

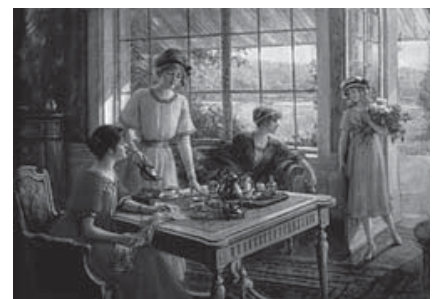

2. А. Линч. Женщины, принимающие чай

Покойная старость, прекрасная молодость, благородство в отношениях, почтительность к возрасту и т.д., и т.д., - «чайные сюжеты» викторианской живописи словно взяты из своеобразного каталога буржуазных добродетелей. Того самого каталога, который можно составить на основе самых душещипательных сентиментальных романов. Трезвый английский ум подчинился эмоциональным запросам нового заказчика. Буржуазные вкусы в данную эпоху транслировали не только представители среднего сословия, ими были захвачены все, вплоть до королевы Виктории, которую нередко называют «королевой-буржуазкой».

Надо сказать, что лишь отдельные современники негативно оценивали новые тенденции английской живописи. Так, Гарри Квилтер, художественный критик «Spectator» и «The Times» упрекал заказчиков картин: «эти современные покровители искусства не хотят покупать ничего другого, кроме приятного, банального и милого, как будто их галереи - это большие коробки конфет...» [2, с. 244]. Большинство же авторов считали подобное 
положение дел не только объяснимым, но естественным. На страницах очень респектабельного и популярного «Art Journal» в 1863 году в ремарках на выставку, проходившую в стенах Королевской академии, было написано: «Англичане, счастливые в своих домах и довольные у своих семейных очагов, чрезвычайно удовлетворены художественной школой, посвященной изображению домашней жизни» [3, с. 192]. А в «Blackwood's Magazine» анонимный обозреватель восклицал: «Художники не мечтают о чем-то неживописном, вроде избирательного права или избирательных бюллетеней. Они идут в деревенские дома все еще счастливой старой доброй Англии. И до тех пор, пока мать души не чает в своем ребенке, до тех пор, пока муж преуспевает в своей работе и счастлив со своей трубкой и элем, до тех пор, пока здоровые, загорелые дети идут веселой гурьбой собирать колосья на полях, до тех пор, пока солнце светит в окна коттеджей и приносит улыбку на каждое лицо, могут ли политические проблемы волновать крестьянина или художника? Что может добавить политик ко всему тому, что дала человеку добрая природа?» [2, с. 194].

Восторженная апологетика сытой обывательской жизни была одной из самых распространенных интонаций не только в искусстве, но во всех сферах викторианской жизни. Вот почему тема чаепития, представленная как важный элемент беспроблемной повседневности, была так востребована в живописи.

Викторианское чаепитие - это всегда занятие камерное, домашнее. Остались в прошлом изображения торжественных приемов, просторных гостиных с большим количеством гостей. В новую эпоху художники редко собирали за столом более 3-4 человек: только члены семьи или близкие друзья. При этом мир английских чайных полотен - это мир женский. Дамы в кругу подруг, рядом с детьми, вместе со служанками - все эти сцены обходятся без лиц мужского пола. Но даже если на картине появляется муж, отец, возлюбленный, родственник, главным действующим лицом всеравно остается женщина. Словосочетание «действующее лицо» имеет в данном случае самый непосредственный смысл: женщина, как правило, чем-то занята, а мужчина остается малоподвижным и вальяжным. Принимает чашку чая из рук стоящей перед ним девушки пожилой джентльмен на картине Дж. Г. Килберна «Теплый гостеприимный дом» (Georg Goodwin Kilburn «A warm welcome home»); поглаживает сидящую рядом собаку Лорд Бекенхед на картине Леонарда Кемпбелла «Летний полдень в интерьере» (Leonard Campbell Taylor «Summer afternoon an interior»), развалившись на диване, курит Роальд Кристиан на полотне Вальтера Ричарда Сикерта «Маленькое чаепитие» (Walter Richard Sickert «The Little Tea Party»). Что-то делать в доме, готовить чай мужчина начинает только в том случае, если он стар и одинок, как на картинах Чарльза Спенслейя (Charles Spencelayh) «Приготовление чая», «Кто-то идет на чай» и др.

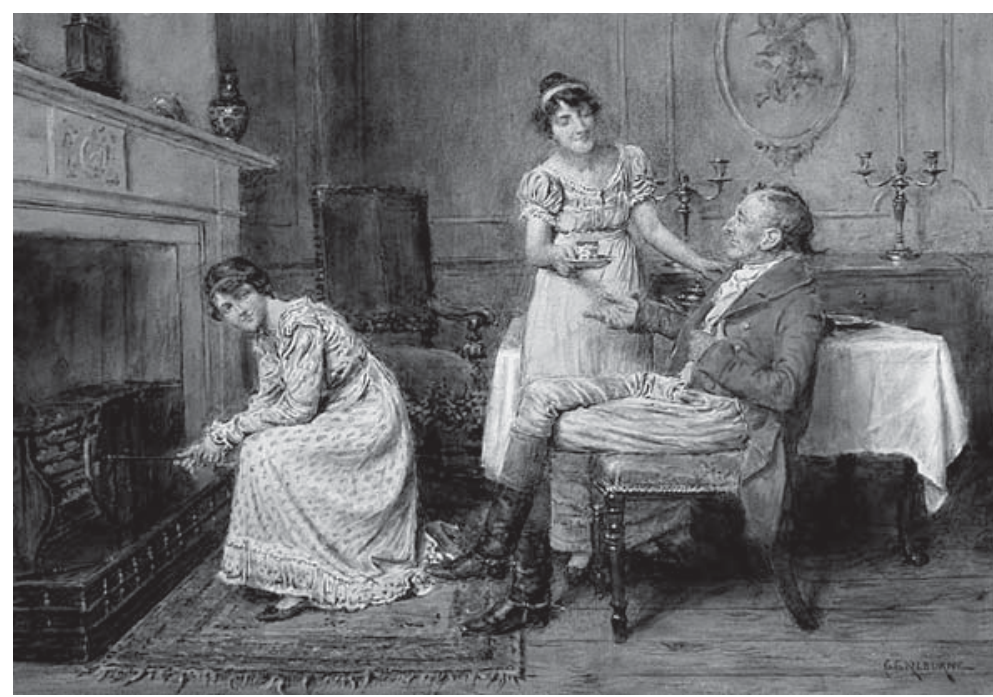

3. Дж. Г. Килберн. Теплый гостеприимный дом

Будучи полностью зависимой от мужа или отца в экономическом плане, в повседневной жизни семьи женщина играла важнейшую роль: «В то время как джентльмены были заняты важными делами, их жены управляли домом и детьми, приглядывали за слугами. Леди должна была уметь в любое время хорошо принять многочисленных и частых гостей любого уровня и быть обворожительной собеседницей в компании и прекрасной партнершей на балах и приемах» [4, с. 125].

За чайным столом царила хозяйка дома. Она заваривала и разливала чай (необходимо напомнить, что это воспринималось не только как привилегия, но и как важная обязанность, высокая миссия), а, следовательно, и по своей роли, и по визуально воспринимаемой «чайной мизансцене», женщина оказывалась центром происходящего. Именно она «приводила в действие» всю правильную последовательность ритуала, следила за соблюдением норм и приличий. 
В итоге женщина становилась главным действующим лицом английского процесса «визуального присвоения» чая. Мужчины чай поставляли и продавали. Женщины чай покупали и сервировали. И как бы не были неравнозначны эти функции, все, что делала женщина, было обязательной частью повседневности, повторялось изо дня в день, было на виду у всех. Визуальная формула английского чаепития прежде всего включала изящную английскую леди, элегантно и неспешно разливающую любимый напиток. Это можно сравнить с тем, что происходит в театре, когда сотни людей готовят спектакль за кулисами, но его успех аккумулируется в актерах, стоящих на авансцене.

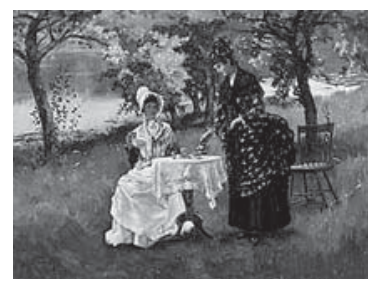

4. Р. Х. Николс. Лето. Послеобеденный чай.

Немаловажно и то, что данная женская роль легко поддавалось визуализации. За вторую половину XIX столетия английскими художниками создано множество женских изображений у чайного стола. Разрабатывались общие мизансцены, продумывались конкретные позы, повороты головы, движения рук. Английская леди наливает чай. Английская леди протягивает гостю чашку. Она же задумчиво и отрешенно сидит с чашкой в руке. Все эти варианты доводились до уровня клише, закреплялись в подсознании зрителя в виде хорошо усваиваемых формул.

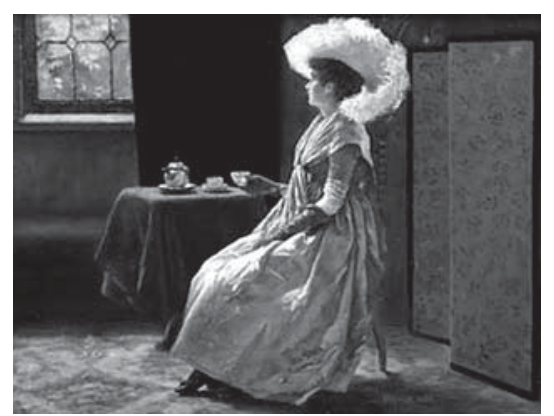

5. Р. Т. Мойнен. Послеобеденный чай

Примечательно, что британские художники последовательно разводили две ипостаси женщины, две ее главные роли: она либо за- ботливая мать, либо верная жена. Мужчины и дети в пространстве дома, созданного викторианской живописью, живут раздельно и пересекаются чрезвычайно редко. Такие изобразительные нормы сформировались только в XIX столетии. В предшествующую эпоху существовало множество картин жанра, получившего название «conversation pieces» («сцены собеседования»), на которых дети участвовали в чаепитии вместе с родителями. За подобными изображениями не стояло никакой реальности: дети в аристократических и буржуазных семьях всегда пили чай отдельно, с гувернантками и няньками. Дистанция между отцом и детьми, матерью и детьми на протяжении всего XVIII века была равно велика. Собирая всю семью на полотне, художник преследовал исключительно задачи портретной репрезентации, мало согласовывая ее с реальными практиками.

Что касается викторианской живописи, то здесь очевидно стремление нарисовать иную модель отношений: оставив непреодолимой дистанцию между отцом и детьми, художники резко сократили дистанцию между детьми и матерью. Чаепитие рисовалось как время и место, оправдание и мотивация для их сближения и общения. На полотне «Завтрак. Утренние игры» Чарлз Уэст Коуп (Charles West Cope «Breakfast time. Morning games») изображает мать и двух ее маленьких дочерей. Собравшись вместе выпить утреннего чаю, они отвлеклись на совместные игры. Так мила и трогательна маленькая белокурая девочка, так изящна и в то же время заботлива ее мать, что картина воспринимается как некий визуализированный образец викторианских отношений дочки-матери, где все участники словно сошли со страниц детских книжек про хороших детей и дружные семьи.

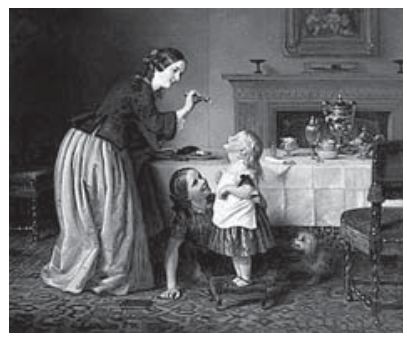

6. Ч. У. Коуп. Завтрак. Утренние игры

На картине Дж. Г. Килберна «Чай в детской» («Теа in the nursery») мать со своими чадами наблюдает за котятами. Ее лицо почти не выражает эмоций, но мягким жестом она 
обнимает младшую дочку, и в этом жесте видится желание Килберна показать теплоту и близость их отношений. Однако в позе девочки видна застенчивость, даже скованность, она явно не привыкла к такому близкому контакту. Гораздо естественнее чувствуют себя дети, стоящие поодаль от матери.

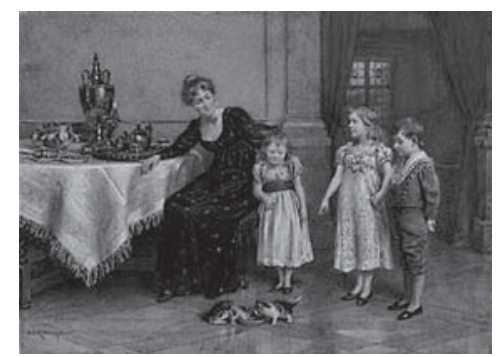

7. Дж. Г. Килберн. Чай в детской

Нарочитость, сочиненность этих и десятков подобных сюжетов становится еще более очевидной при сравнении их, например, с картиной Хильды Фирон «Чаепитие» (Hilda Fearon «The Tea Party»), написанной несколько позже - в 1916 году - и находящейся уже за пределами точных хронологических рамок викторианской эпохи. Ее героиня просто сидит за чайным столом вместе с двумя детьми, просто держит на коленях сына, доверчиво прижавшегося к ней, и в этих позах такая степень близости, такая общность настроения, такая привычность совместного времяпрепровождения, которые не надо расшифровывать и усиливать, придумывая героям дополнительные общие занятия. На фоне картины Х.Фирон все предшествующие работы смотрятся как театральные постановки, в которых для действующих лиц прописаны клишированные занятия из набора «родители проводят время с детьми».

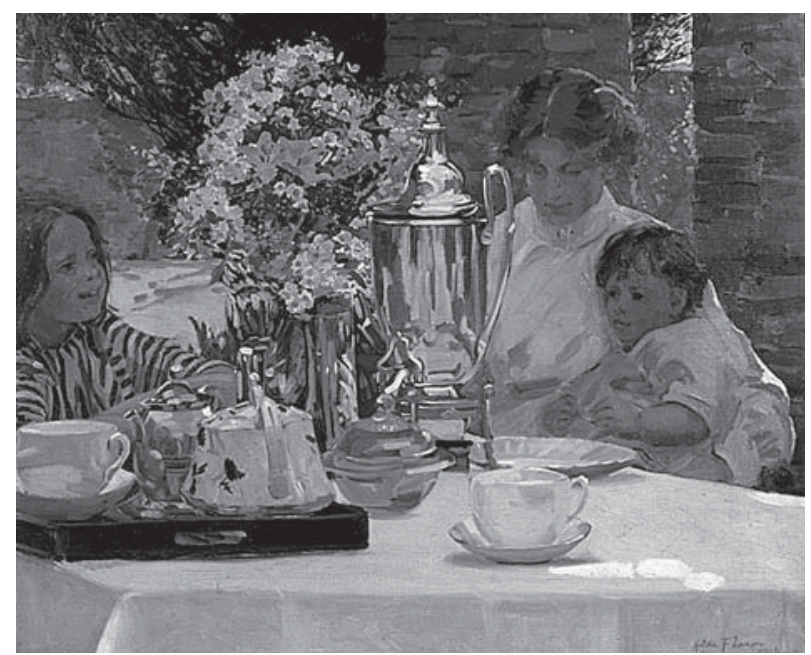

8. Х. Фирон. Чаепитие
За нарочитостью композиций стоит реальная жизнь викторианской Англии: «Главное правило, которому учили детей с пеленок, заключалось в том, что они должны быть видны, но не слышны. Находясь целый день под присмотром няни, а позже гувернанток или гувернеров и большую часть времени проводя в детской, нередко они видели маму и папу, только когда заходили в гостиную пожелать им спокойной ночи» [4, с. 132]. Показательно, однако, само желание многих авторов убрать дистанцию между матерью и детьми, показать повышенную теплоту и близость их отношений. Подобное стремление указывало не на бытовавшие в социуме нормы, а на формирующиеся идеалы. Художники рисовали благостные сцены, говорили о культе семьи, о семейных добродетелях, но «проговаривались» о викторианской дистанции между детьми и родителями, об отстраненной сдержанности их отношений.

Очень часто желание убрать из картин холодноватую ноту взаимоотношений оборачивалась повышенной сентиментальностью произведений. Такая «сладостность» изображенных сцен не казалось британским зрителям нарочитой или избыточной. Возникает ощущение, что она играла своеобразную компенсаторную роль в обществе, где люди всегда чрезвычайно сдержанны в проявлении своих чувств.

Однако нигде более викторианская сентиментальность, желание писать «приятное и милое» не проявлялась в такой степени, как при изображении детского чаепития. Эта тема в английской «чайной живописи» уникальна. В других европейских художественных школах она представлена единичными произведениями (в России ее вообще не было), в английской же она была распространена чрезвычайно широко. Милыми малютками, пьющими чай, любовались все, а тон, как это часто бывало, задавала королева Виктория. Ее любимым художником был Чарльз Бартон Барбер (Charles Burton Barber). Художник чаще всего писал милых крошек, в основном, маленьких белокурых девочек, пьющих чай вместе со своими столь же милыми питомцами («Молитва», «Время для чая»). Крайняя степень сентиментальности, соединенная с технической виртуозностью буквально завораживали заказчиков и покупателей полотен. 


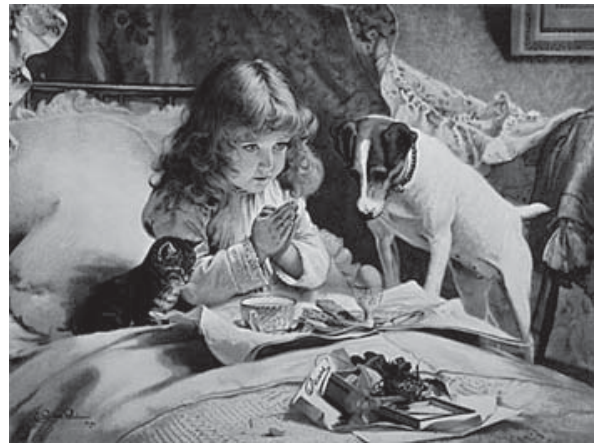

9. Ч. Б. Барбер. Молитва

А кроме Ч.Б. Бартона на подобных сюжетах специализировались Артур Джон Эйлсли (Arthur John-Elsley), Гарри Брукер (Harry Brooker) и другие. На их полотнах дети либо пьют чай в компании своих сверстников, либо играют «в чаепитие» с куклами, либо разделяют этот ритуал с домашними животными, но в любом варианте они старательно подражают манерам, движениям и позам взрослых. Распространенность подобных сюжетов выступает одним из самых убедительных доказательств глубокого проникновения чайного ритуала в британскую жизнь. Он стал неотъемлемой частью повседневности, которая усваивалась как совершенно естественная с самого детства, и которая не предполагала специального обучения, как это было в случае с иностранными, привнесенными практиками.

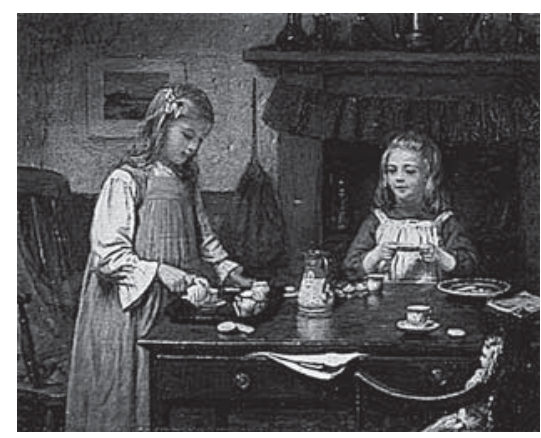

1о. Г. Брукер. Чаепитие

И в детском, и во взрослом исполнении британский чайный ритуал предъявлял повышенные требования к внешнему облику участников. Чаепитие ни в коем случае не рассматривалось как простое утоление жажды, это - Событие, даже несмотря на то, что оно повторялось каждый день, или даже несколько раз в день. Ни один художник «не застал врасплох» своих персонажей, не написал их небрежными в одежде или с беспорядком в прическе. В контексте викторианской чайной живописи невозможно представить даже «чаепитие в халате», достаточно распространенное в XVIII веке. Такие трансформации свидетельствуют о произошедших изменениях не столько в самом чаепитии, сколько в задачах его репрезентации. Изображение становилось образцом, своеобразной рекламной картинкой, визуализирующей правила приличия, нормы поведения истинного британца. Данные нормы обязательно включали требования «быть застегнутым на все пуговицы», не впускать никого в личное пространство, демонстрировать окружающим свою «парадную» сторону.

Викторианская живопись, конечно же, отражала процессы демократизации, затронувшие потребление чая в стране. Именно в данный период на английских чайных полотнах появились представители низших сословий. Художники тщательно прорисовывали небогатую, или даже бедную обстановку дома: глиняный или деревянный пол, грубоватую мебель, тусклые краски интерьера. Детально выписывали простые одежды персонажей, отсутствие каких-либо украшений. Однако при этом чайный стол всегда показан покрытым скатертью, на столе стоят не просто чашки, а фарфоровый сервиз. О том, что этот фарфор намного более дешевый, чем на полотнах, посвященных аристократическому чаепитию, может сказать только специалист. Позы и жесты персонажей лишь слегка менее изящны, чуть более скупы и просты. В них нет той изломанности и жеманности, которой наделяли своих аристократических персонажей некоторые художники, стремясь подчеркнуть их врожденную элегантность. Однако в них читается значительность, чувство собственного достоинства, понимание серьезности осуществляемого ритуала.

В изображенном интерьере, как на картине Тома МакЭвана «Чаепитие» (Tom McEwan «Tеa Time»), могут ходить куры, на полу деревенского коттеджа лежать различные овощи, но на чайном столе представлен идеальный порядок (все та же белая скатерть, фарфоровый сервиз, включающий молочник, масленку, чашки с блюдцами), в одежде людей - никакой небрежности. Большинство персонажей на подобных полотнах ведут себя так, словно они знакомы с основными правилами чайного этикета. Никто не кладет локти на стол, все демонстрируют сдержанность и неспешную значительность движений. 


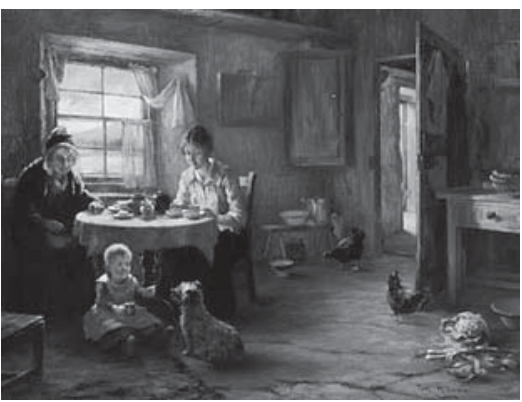

11. Т. МакЭван. Чаепитие

За подобными трактовками, конечно же, стояла и ощутимая степень дидактики, характерная для всего английского искусства викторианской эпохи, и желание соответствовать представлениям зрителя о том, какой должна быть «чайная живопись». Но в любом случае применительно ко второй половине XIX века можно говорить о существовании британского, общенационального, независимого от социального положения и достатка, представления о чаепитии.

Таким образом, начиная с викторианской эпохи выражение «английское чаепитие» стало понятным и обычным, приобрело устойчивую смысловую наполненность. Англичане окончательно присвоили импортируемый напиток, адаптировали, перекодировали практики, с ним связанные. Живопись была активным участником этого процесса. Она не блистала громкими именами, известными работами и в целом была мало знакома за пределами Великобритании. Но, сохраняя достаточно высокий средний уровень мастерства, профессионализм, а также желание услышать новый социальный заказ и адекватно ответить на него, она была чрезвычайно востребована, вошла в каждый буржуазный английский дом второй половины XIX столетия.

Согласно «Словарю английских художников» [5], в викторианскую эпоху работало более 11 тысяч живописцев, причем большая их часть специализировалась на бытовом жанре. Десятки и сотни художников трудились над визуализацией того, что получило название «английское чаепитие», помогая ввести чайный ритуал в качестве неотъемлемой части в британскую повседневность. Его связь с национальными идеалами о благополучной, комфортной, неспешной, защищенной жизни несомненна. Живопись не только отражала существовавшие в социуме идеалы, но и, давала их устойчивые образцы, укрепляла их в обществе. Присвоив внутренне, осознав чаепитие, как исключительно «свое», национальное занятие, британцы смогли транслировать его на весь мир.

\section{Библиография:}

1. Beddoes, E. The art of tea: late Victorian visual culture and the normalization of an international national icon. 2014. [Electronic resource] // University of Birmingham. URL: http://etheses.bham.ac.uk/4915.

2. Johnson, E.D.H. Painting of the British social scene from Hogarth to Sickert. London: Weidenfeld and Nicolson, 1986. 287 p.

3. The Royal Academy // The Art Journal. 1863.

4. Диттрич Т.В. Повседневная жизнь викторианской Англии. М.: Молодая гвардия, 2007. 382 с.

5. Christopher Wood. The dictionary of Victorian painters. Woodbridge: Antique Collectors' Club, 1971. 435 p.

\section{References (transliterated):}

1. Beddoes, E. The art of tea: late Victorian visual culture and the normalization of an international national icon. 2014. [Electronic resource] // University of Birmingham. URL: http://etheses.bham.ac.uk/4915.

2. Johnson, E.D.H. Painting of the British social scene from Hogarth to Sickert. London: Weidenfeld and Nicolson, 1986. $287 \mathrm{p}$.

3. Dittrich T.V. Povsednevnaya zhizn' viktorianskoi Anglii. M.: Molodaya gvardiya, 2007. 382 s.

4. Christopher Wood. The dictionary of Victorian painters. Woodbridge: Antique Collectors' Club, 1971.435 p. 